\title{
Platelet Fc Receptor
}

\section{INCREASED EXPRESSION IN MYELOPROLIFERATIVE DISEASE}

\author{
AnNe Moore and Ralph L. Nachman, Division of Hematology-Oncology, \\ Department of Medicine, The New York Hospital-Cornell University \\ Medical Center, New York 10021
}

\begin{abstract}
A B S T R A C T The platelet Fc receptor, a membrane receptor for immune complexes or aggregated immunoglobulin (Ig)G, was compared in normal and myeloproliferative platelets. Washed platelets from 11 normal donors and 27 patients were incubated with fluorescein-conjugated ovalbumin-anti-ovalbumin complexes and examined by phase and fluorescence microscopy. Only $3.2 \pm 1 \%$ of the normal platelets stained, whereas $76 \pm 16 \%$ of the myeloproliferative platelets stained with the immune complex. The fluorescent staining was mediated by a platelet $\mathrm{Fc}_{\mathrm{c}}$ receptor, as shown by the absence of platelet staining with immune complex containing antibody preincu= bated with Staphylococcal protein A to block the $\mathrm{Fc}$ region. In addition, no staining occurred with antigen or antibody alone or after preincubation of platelets with aggregated IgG. Platelets from normal or myeloproliferative donors did not stain with the immune complexes when the incubation was performed in plasma. The increased expression of $\mathbf{F c}$ receptors on myeloproliferative platelets was corroborated by studies of $\left[{ }^{14} \mathrm{C}\right]$ serotonin release by immune complexes or aggregated IgG in 8 patients and 17 normal donors. Serotonin uptake was similar in both groups. Myeloproliferative platelets released significantly more serotonin than normal platelets at each concentration of immune complex or aggregated IgG; in addition, myeloproliferative platelets released serotonin in response to much smaller concentrations of immune complex or aggregated IgG. $\left[{ }^{14} \mathrm{C}\right]$ Serotonin release by myeloproliferative platelets was not increased above that of normal platelets when thrombin was used as the stimulus. The results were independent of patient age, sex, therapy, hematocrit, or platelet size. Interaction of circulating immune com-
\end{abstract}

Part of this work has been published previously in abstract form. 1979. Blood. 54: 254A.

Received for publication 2 May 1980 and in revised form 26 November 1980. plexes with platelets bearing increased $F c$ receptors may contribute to the abnormal hemostasis associated with the myeloproliferative syndromes.

\section{INTRODUCTION}

Hemorrhage and thrombosis frequently complicate the clinical course of patients with the myeloproliferative diseases, polycythemia vera, myelofibrosis, and essential thrombocythemia. Quantitative as well as qualitative abnormalities of platelets may contribute to this disordered balance of hemostasis. Thrombocytosis is present in the majority of patients with polycythemia vera (1), in one-third of patients with myelofibrosis (2), and is the major hematologic problem in patients with essential thrombocythemia. Although the high platelet count predisposes to thrombosis or hemorrhage, these events may occur in the setting of a normal platelet count (3). Qualitative abnormalities which are common in myeloproliferative platelets include abnormal platelet morphology $(4,5)$ and an absent aggregation response to epinephrine (6). Recently, decreased numbers of $\alpha$-adrenergic receptors were described in platelets of two patients with essential thrombocythemia (7). Altered platelet metabolism of the prostaglandin precursor arachidonic acid has been reported in myeloproliferative platelets. The recent demonstration of a selective lipoxygenase deficiency in myeloproliferative platelets suggests that there may be a reciprocal increase in the cyclooxygenase pathway with subsequent increased aggregability of the myeloproliferative platelets (8). Prostaglandin $\mathrm{D}_{2}$, a product of the cyclooxygenase pathway, inhibits platelet aggregation. Resistance to prostaglandin $\mathrm{D}_{2}$ and loss of prostaglandin $\mathrm{D}_{2}$ receptors on myeloproliferative platelets may also contribute to a thrombotic state $(9,10)$.

Circulating immune complexes have been reported in the plasma of patients with myelofibrosis (11). Immune complexes may interfere with platelet func- 
tion through interaction with a platelet $\mathrm{Fc}_{\mathrm{c}}$ receptor $(12,13)$. We have previously reported on the interaction of a fluorescein isothiocyanate (FITC) ${ }^{1}$-conjugated immune complex, keyhole limpet hemocyanin (KLH)-anti-KLH, with human platelets (14). The majority of normal platelets bear a surface $\mathrm{Fc}_{\mathrm{c}}$ receptor for this immune complex. In the present study, we describe an FITC-conjugated immune complex, ovalbumin-anti-ovalbumin, which reacts with only a small percentage of normal platelets. We have used this specific immune complex, as well as heat-aggregated human immunoglobulin $(\mathrm{Ig}) \mathrm{G}$, as a probe to study the differences between the $F_{c}$ receptor of myeloproliferative platelets and of normal platelets.

\section{METHODS}

Preparation of platelets. Platelet-rich plasma (PRP), washed platelets, and fixed washed platelets were prepared from whole blood as previously described (14). Platelet counts were performed visually under phase-contrast microscopy and electronically using the model ZBI Coulter counter (Coulter Electronics, Inc., Hialeah, Fla.) according to the methods outlined by Gottfried et al. (15). Platelet sizing was carried out in PRP from blood drawn into ACD. A size distribution analyzer was used (Coulter model $P_{64}$ ), coupled with the model ZBI Coulter Counter fitted with a $70-\mu \mathrm{m}$ aperture tube. The equipment was calibrated using $2.02 \mu \mathrm{m}^{3}$ latex particles (Coulter Electronics). The median Coulter volumes were calculated according to the method of von Behrens (16).

Preparation of immune complexes and aggregated human IgG. The preparation of the FITC-conjugated KLH-rabbit anti-KLH complex has been previously described (14). Rabbit antiserum to ovalbumin was prepared by immunization of rabbits with chicken egg albumin (Sigma Chemical Co., St. Louis, Mo.). The IgG was isolated by column chromatography of the antiserum on DEAE-cellulose (DE-52, Whatman Chemicals, Div. W. \& R. Balston, Maidstone, Kent, England). The ovalbumin and the anti-ovalbumin IgG were conjugated to FITC at final ratios of FITC to protein of 0.5 (ovalbumin) and 1.1 (anti-ovalbumin) $\mu \mathrm{g} / \mathrm{ml}$.

Human IgG was prepared from pooled normal serum as previously described and heat aggregated by incubation at $63^{\circ} \mathrm{C}$ for $10 \mathrm{~min}$ just before use (14).

Conjugation of protein A to IgG. To block the Fc region of IgG, the rabbit and the human IgG preparations were conjugated to protein A (Pharmacia Fine Chemicals, Piscataway, N. J.) by the method described by Rabellino et al. (17).

Fluorescence assay for platelet $F_{c}$ receptors. Platelets were incubated with immune complexes, washed, and examined by phase and fluorescence microscopy as previously described (14). FITC-ovalbumin $(30 \mu \mathrm{g} / \mathrm{ml})$ and FITCanti-ovalbumin $(3.5 \mathrm{mg} / \mathrm{ml})$ were used. This ratio of antigen to antibody is in the range of antibody excess as determined by the method of Winchester et al. (18), and gave maximal discrete platelet staining with minimal platelet clumping. The specificity of the staining reaction for the immune complex was demonstrated by the absence of staining with FITC-conjugated antigen or antibody alone. The specificity

1 Abbreviations used in this paper: FITC, fluorescein isothiocyanate; KLH, keyhole limpet hemocyanin; PRP, platelet-rich plasma. of the staining reaction for $\mathrm{Fc}_{\mathrm{C}}$ receptors was demonstrated by the absence of staining with antigen and antibody conjugated to protein $\mathrm{A}$. In addition, preincubation of the platelets for $30 \mathrm{~min}$ with heat-aggregated IgG, 100$1,000 \mu \mathrm{g} / \mathrm{ml}$, blocked the subsequent staining with immune complexes, whereas preincubation with unaggregated IgG had no effect. Platelets in plasma (PRP) did not stain with the FITC-conjugated immune complex.

To test the effect of thrombin on the expression of the platelet $F_{c}$ receptor, platelets were washed as described above, except that $4 \mathrm{mM}$ EDTA was added to the buffer. $5 \times 10^{8}$ platelets were incubated with thrombin $0.25 \mathrm{U} / \mathrm{ml}$ at $37^{\circ} \mathrm{C}$ for $5 \mathrm{~min}$. The platelets were then washed twice with buffer containing $1 \mathrm{mM} p$-tosyl-L-arginine methyl ester, and the platelet $\mathrm{Fc}_{\mathrm{C}}$ receptor assay was performed.

Preincubation of platelets with von Willebrand factor and ristocetin was performed as previously described (14).

Serotonin release by aggregated IgG, immune complexes, or thrombin. PRP was prepared as described above, centrifuged once at $600 \mathrm{~g}$, and resuspended to a platelet count of $4 \times 10^{8} / \mathrm{ml} .1 .5 \mu \mathrm{l}\left[2^{\prime}-{ }^{14} \mathrm{C}\right] 5$-hydroxytryptamine creatinine sulfate $(50 \mu \mathrm{Ci} / \mathrm{mmol}$ sp act, Amersham Corp., Arlington Heights, Ill.) was added per milliliter suspended platelets, and after incubation in a circulating water bath at $37^{\circ} \mathrm{C}$ for $15 \mathrm{~min}$, samples were taken to assess the uptake of serotonin. The platelets were then washed two times and resuspended at $15 \times 10^{8} / \mathrm{ml}$ for the experiments using immune complex, $6.5 \times 10^{8} / \mathrm{ml}$ for the experiments using aggregated IgG, and $5 \times 10^{8} / \mathrm{ml}$ for the thrombin experiments. $1 \mu \mathrm{M}$ imipramine was added to prevent re-uptake of released serotonin. 200 $\mu$ l samples of washed platelets were distributed to $1.5-\mathrm{ml}$ conical capped polypropylene tubes for the experiments using immune complexes or thrombin, and $100-\mu 1$ portions were used for the experiments using aggregated IgG. For the experiments using immune complexes as the stimulus to platelet serotonin release, $25 \mu \mathrm{l}$ of anti-ovalbumin $(0.35$ $\mathrm{mg} / \mathrm{ml}$ ) and $25 \mu \mathrm{l}$ of serial dilutions of ovalbumin (100 $\mu \mathrm{g} / \mathrm{ml}$, final concentration of undiluted ovalbumin) were added. Antibody and antigen were also tested alone. For the experiments using human IgG, $100 \mu \mathrm{l}$ of serial dilutions of aggregated or unaggregated IgG $(6.85 \mathrm{mg} / \mathrm{ml}$, final concentration of undiluted IgG) was added. After incubation in a circulating water bath at $37^{\circ} \mathrm{C}$ for $30 \mathrm{~min}$, the tubes were immersed in an ice bath and centrifuged at $8,000 \mathrm{~g}$ for $30 \mathrm{~s} ; 100-\mu \mathrm{l}$ samples of each supernate were placed in scintillation vials containing $2.7 \mathrm{ml}$ of Biofluor (New England Nuclear, Boston, Mass.). The radioactive samples were counted in a Searle Mark III liquid scintillation counter (Searle Diagnostics, Inc., Des Plaines, Ill.). To measure serotonin release by thrombin, $25-\mu$ l samples of purified human thrombin (a gift from Dr. J. Fenton, Albany, N. Y.) in serial dilutions were added to the platelet suspensions. The final concentration of thrombin in the original dilution was $9.5 \mathrm{U} / \mathrm{ml}$. The incubation procedure was performed according to the method of Weksler et al. (19). In some experiments, the lactic dehydrogenase (LDH) activity was measured in the supernate of the experimental samples and compared to the LDH activity in the supernate of the control samples (20).

Normal and patient donors. The characteristics of the normal and patient donors are outlined in Table I. The age, hematocrit, platelet count, and platelet size are noted. The normal donors were taking no medication and the absence of recent aspirin ingestion was confirmed by testing platelet aggregation in response to arachidonic acid (19). The fluorescence assay for the platelet $\mathrm{Fc}$ receptor was also performed on three of the normal donors before and $12 \mathrm{~h}$ after the ingestion of $650 \mathrm{mg}$ aspirin. Aggregation response to 
TABLE I

Characteristics of Normal and Patient Donors

\begin{tabular}{lccccc}
\hline \multicolumn{1}{c}{ Diagnosis } & Number & Age & Hematocrit & Platelet count & Platelet size \\
\hline & & $y r$ & $\%$ & $\times 10^{3} / \mu l$ & $\mu m^{3}$ \\
Normal donors & 21 & 31 & 40 & 275 & $5.8(6)^{*}$ \\
& & $(22-64)$ & $(34-48)$ & $(150-396)$ & $(4.7-6.5)$ \\
$\begin{array}{l}\text { Myeloproliferative } \\
\text { syndrome }\end{array}$ & 28 & 63 & 38 & 634 & $6.4(9)^{*}$ \\
$\begin{array}{l}\text { Chronic myelogenous } \\
\text { leukemia }\end{array}$ & 4 & $(35-76)$ & $(22-55)$ & $(197-2400)$ & $(4.95-11.12)$ \\
$\begin{array}{l}\text { Reactive } \\
\text { thrombocytosis } \$\end{array}$ & 9 & 50 & 45 & 144 & ND \\
Miscellaneous & & $(25-68)$ & $(30-55)$ & $(100-666)$ & $6.1(3)^{*}$ \\
& 11 & $(22-78)$ & $(29-41)$ & $(500-1500)$ & $(5.3-7.2)$ \\
& & $(43-87)$ & $(20-40)$ & $(108-300)$ & $(5.1-5.5)$ \\
\hline
\end{tabular}

This table characterizes the total pool of normal and patient donors from which those used for Fc receptor staining and for serotonin release studies by aggregated IgG or immune complexes were drawn. Some donors were used for both assays; some only for one or the other. ND, not done.

* Number tested.

\$ Myelofibrosis, 12; polycythemia vera, 13; essential thrombocythemia, 3 .

\$Infection, 5; postsplenectomy, 2; carcinoma of lung, 1; etiology unknown, 1.

"Carcinoma or lymphoma, 5; immune thrombocytopenia purpura in remission, 2; acute myelogenous leukemia, 1; femoral fracture, 1; megaloblastic anemia, 1; cerebrovascular accident, 1.

$20 \mu$ epinephrine $\mathrm{HCl}(1: 1,000$, Parke-Davis, Detroit, Mich.) added to $0.45 \mathrm{ml}$ of PRP was tested in 16 patients with the myeloproliferative syndrome. There was no response to epinephrine in nine patients.

The patients with myeloproliferative syndrome were in all stages of the disease, including newly diagnosed, controlled on medication, and terminal phases. They were receiving various non-aspirin-containing medications; eight of the patients were taking no medication. Three patients had undergone splenectomy. The assays requiring platelet serotonin release were only performed on patients whose platelet counts were $>200 \times 10^{3} / \mu l$.

\section{RESULTS}

\section{Platelet Fc receptor staining}

Normal donors. The platelets of 11 normal donors were reacted with the FITC-conjugated immune complex ovalbumin-anti-ovalbumin; one donor was studied on eight separate occasions. The mean number of platelets stained was $3.2 \pm 1.1 \%$; no more than $5 \%$ platelets were stained in any normal donor preparation (Fig. 1). Aspirin ingestion had no effect on the staining pattern.

Individual platelets stained in a focal or spotty pattern, there was no diffuse staining (Fig. 2a,b). Rarely, a crescent pattern of staining was seen (Fig. $2 \mathrm{c}, \mathrm{d})$. The fluorescent staining was not limited to large or small platelets, and it was impossible to predict by phase microscopy which platelets would or would not stain (Fig. 2e,f). Optimal staining occurred when the complex was used in a ratio of antibody excess. When the immune complex was used in a ratio of antigen excess, large platelet aggregates and fluorescein clumps were formed, and very little individual platelet staining was detected. Fixed washed platelets did not stain with the immune complex.

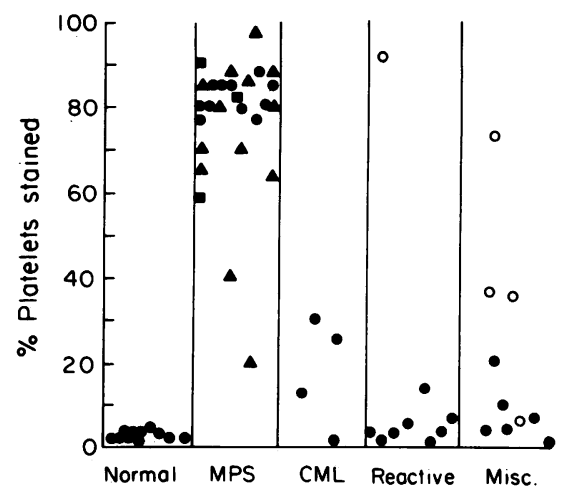

Figure 1 Percentage of platelets stained by the FITCconjugated immune complex, ovalbumin-anti-ovalbumin. The mean values \pm one SD are normal, $3.2 \pm 1.1 \%$; myeloproliferative syndrome (MPS), $76.4 \pm 16 \%$; chronic myelogenous leukemia (CML), $20.1 \pm 16 \%$; reactive thrombocytosis, $14 \pm 28.6 \%$; miscellaneous, $19.6 \pm 22.3 \%$. MPS: polycythemia vera, $\Delta$; agnogenic myeloid metaplasia, ; essential thrombocythemia, a. Reactive thrombocytosis and miscellaneous: cancer or lymphoma, $\bigcirc$; all others, 


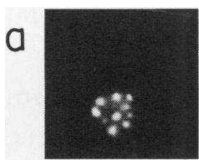

b

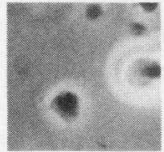

C

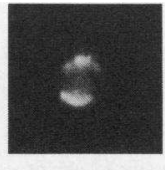

d

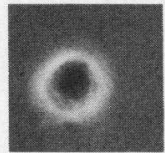

e
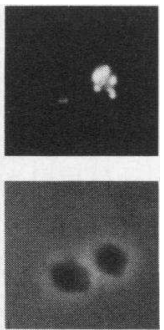

Figure 2 Washed normal platelets incubated with the FITC-conjugated immune complex, ovalbumin-anti-ovalbumin. The lower panels are phase photomicrographs of individual platelets; the upper panels are fluorescence photomicrographs of the same field (magnification $\times 1,500$ ).

As previously reported, the FITC-conjugated KLHanti-KLH complex stained $80-90 \%$ of normal platelets. Although the staining by this complex was markedly reduced by preincubation of platelets with factor VIII:antigen and ristocetin, the platelet staining by ovalbumin-anti-ovalbumin was not affected by preincubation with factor VIII:antigen and ristocetin.

Thrombin treatment of normal platelets did not change the mean number of platelets stained or the pattern of staining.

Myeloproliferative syndrome. Platelets from patients with myeloproliferative disorders were strikingly different from normal platelets (Fig. 3). $76.4 \pm 16 \%$ of the myeloproliferative platelets stained with the immune complex, ovalbumin-anti-ovalbumin (Fig. 1). 18 of the 27 patients had $80 \%$ or more platelets stained; 25 patients had $50 \%$ or more platelets stained.
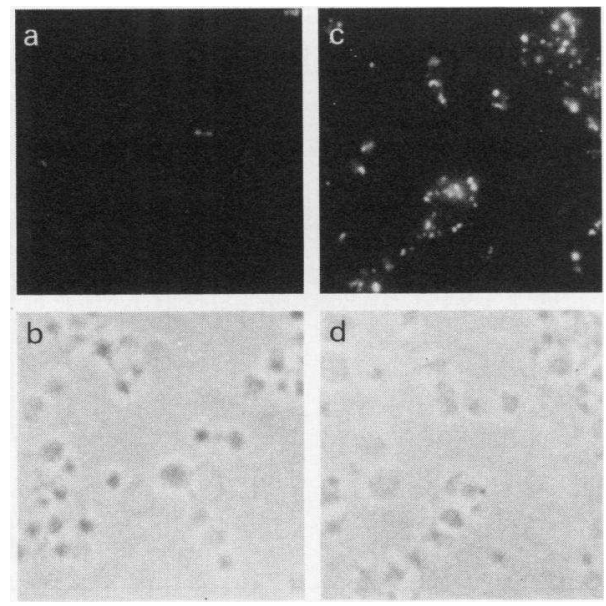

d

Figure 3 Phase and fluorescence photomicrographs of the same field from a preparation of washed normal platelets $(\mathrm{a}, \mathrm{b})$ and a preparation of myeloproliferative platelets (c,d) stained with the immune complex, ovalbumin-antiovalbumin. The fluorescence photomicrographs show a striking increase in staining of the myeloproliferative platelets (magnification $\times 1,500$ ).
Two patients with polycythemia vera repeatedly had 20 and $40 \%$ platelets stained. Both of these patients had classic polycythemia vera and were clinically no different from patients with $80 \%$ staining. The percentage of positively stained platelets was independent of patient sex, age, hematocrit, platelet count, and mean platelet size. There was no correlation between percentage of platelets stained and prior splenectomy, spleen size, aggregation response to epinephrine, or clinical history of bleeding or thrombosis. One patient with myelofibrosis was studied prior to splenectomy, after splenectomy, while on no medication, while on aspirin ( $325 \mathrm{mg}$ twice daily), and when the platelet count was high $\left(2,000 \times 10^{3 /}\right.$ $\mu \mathrm{l})$ or low $\left(200 \times 10^{3} / \mu \mathrm{l}\right)$. There was no difference in the staining pattern during this sequence.

The pattern of $\mathrm{Fc}$ receptor staining of ovalbuminanti-ovalbumin on individual myeloproliferative platelets was similar to the normal pattern. The optimal staining of myeloproliferative platelets was similar to normal platelets and occurred in the range of antibody excess $(30-60 \mu \mathrm{g} / \mathrm{ml}$ antigen; $3.5 \mathrm{mg} / \mathrm{ml}$ antibody). The myeloproliferative platelets also showed definite but less bright staining at antigen concentrations as low as $3-5 \mu \mathrm{g} / \mathrm{ml}$, a range where staining of normal platelets was no longer detectable. No staining of myeloproliferative platelets was found with FITC-ovalbumin or anti-ovalbumin alone, nor with FITC anti-ovalbumin conjugated to protein A. Prior incubation of myeloproliferative platelets with aggregated human IgG abolished the staining with the FITC-conjugated immune complex.

Myeloproliferative platelets stained in the same manner as normal platelets with the immune complex KLH-anti-KLH.

Chronic myelogenous leukemia. The platelets of four patients with chronic myelogenous leukemia did not demonstrate a striking increase in staining (Fig. 1). One patient had $1.5 \%$ staining; the patient with the highest percentage of stained platelets $(30 \%)$ was in the blast phase of the disease.

Reactive thrombocytosis. Nine patients with reactive thrombocytosis were studied (Fig. 1). The mean percentage of platelets stained with the immune complexes was $14 \pm 28.6 \%$. One patient, a 50 -yr-old woman with carcinoma of the lung and a platelet count of $1,200 \times 10^{3} / \mu \mathrm{l}$, had $90 \%$ stained platelets. There was no clinical evidence of a myeloproliferative disorder in this patient, although a bone marrow biopsy was not performed; in addition, she demonstrated no evidence of a thromboembolic disorder.

Miscellaneous disorders. Among 10 patients hospitalized for a variety of problems, 1 patient with metastatic ovarian carcinoma demonstrated $72 \%$ staining, and 2 patients, a woman with diffuse histiocytic lymphoma and a woman with acute myelogenous 
leukemia in partial remission, demonstrated $35 \%$ staining. The mean percentage of platelets stained in this group was $19.6 \pm 22.3 \%$ (Fig. 1). None of these patients had clinical thromboembolic disease.

Serotonin uptake and release by aggregated IgG and immune complexes in normal and myeloproliferative platelets. Platelet serotonin uptake in 14 normal donors was $85.8 \pm 6.7 \%$. Platelet serotonin uptake was studied in six patients (three myelofibrosis; two polycythemia vera; one essential thrombocythemia). Three patients were on no medication; three patients were taking non-aspirin-containing medication. The mean serotonin uptake in five of six patients was $87 \pm 1.3 \%$. The serotonin uptake by one patient's platelets was 33 and $37 \%$ on two separate occasions.

Platelet serotonin release in response to aggregated IgG was studied in 14 normal donors. Peak serotonin release $(42.6 \pm 18.9 \%)$ by aggregated IgG was found at a final concentration of $438 \mu \mathrm{g} \mathrm{IgG/ml} \mathrm{(Fig.} \mathrm{4).} \mathrm{Mean}$ serotonin release $>25 \%$ was found in the range of 55 to $3,500 \mu \mathrm{g}$ aggregated $\mathrm{IgG} / \mathrm{ml}$. Platelet serotonin release in response to aggregated IgG in the five myeloproliferative patients with normal serotonin uptake was found to be markedly increased compared with the normal patients (Fig. 4). Peak serotonin release $(78.8 \pm 9.5 \%)$ by aggregated IgG occurred at $438 \mu \mathrm{g}$ aggregated $\mathrm{IgG} / \mathrm{ml}$. Mean serotonin release $>25 \%$ began at $3.5 \mu \mathrm{g} / \mathrm{ml}$, release $>70 \%$ began at 57 $\mu \mathrm{g} / \mathrm{ml}$ and both continued to the highest concentration, $7,300 \mu \mathrm{g} / \mathrm{ml}$. This pattern was similar in all five patients. There was no relationship to hematocrit (range $26-55 \%$ ), platelet count (range $155-1,800 \times 10^{3} / \mu \mathrm{l}$ ), or platelet size $\left(6.06-11.02 \mu \mathrm{m}^{3}\right)$. There was no serotonin release $>5 \%$ from normal or myeloproliferative platelets by any concentration of unaggregated IgG or by aggregated IgG conjugated to protein $\mathrm{A}$. There was

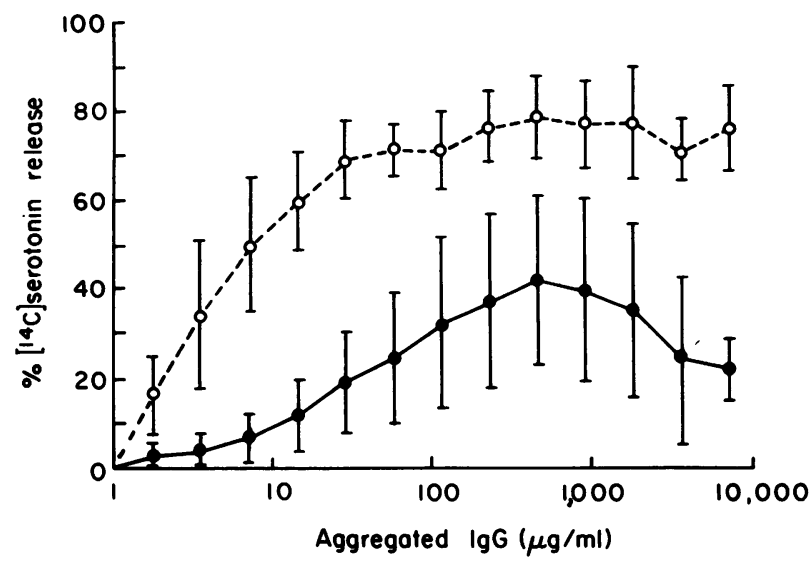

Figure $4\left[{ }^{14} \mathrm{C}\right]$ Serotonin release by heat-aggregated IgG from platelets of 14 normal donors $(O)$ and 5 patients with myeloproliferative syndrome $(O)$. Bars indicate \pm 1 SD. no significant LDH release by aggregated IgG from either normal or myeloproliferative platelets.

Serotonin release from platelets by the immune complex ovalbumin-anti-ovalbumin was studied in three normal donors and three patients with myeloproliferative diseases (two polycythemia vera; one myelofibrosis) (Fig. 5). In both the normal and patient donors, maximum serotonin release occurred in the range of antibody excess. This correlates with the optimal range for staining of washed platelets with the FITC-conjugated immune complex. Myeloproliferative platelets released $>60 \%$ serotonin in response to immune complexes of all antigen-antibody ratios. The maximum serotonin release was $92 \%$. In contrast, normal platelets released a maximum of $39 \%$ serotonin, and $>30 \%$ serotonin only over a small range of antigen concentration $(6-15 \mu \mathrm{g} / \mathrm{ml})$. Neither normal nor myeloproliferative platelets released serotonin in response to antigen or antibody alone, and there was no LDH release after incubation of the platelets with the immune complexes.

The platelets of five patients with myeloproliferative disease and five normal donors were tested for serotonin release in response to serial dilutions of thrombin. There was no increased release of serotonin by the myeloproliferative platelets compared with normal (Fig. 6).

\section{DISCUSSION}

This study demonstrates the increased expression of a platelet $F_{c}$ receptor in myeloproliferative platelets. The interaction between the immune complex and the platelets is dependent on an intact antibody Fc region and is blocked by heat-aggregated IgG. We have previously described the interaction of a

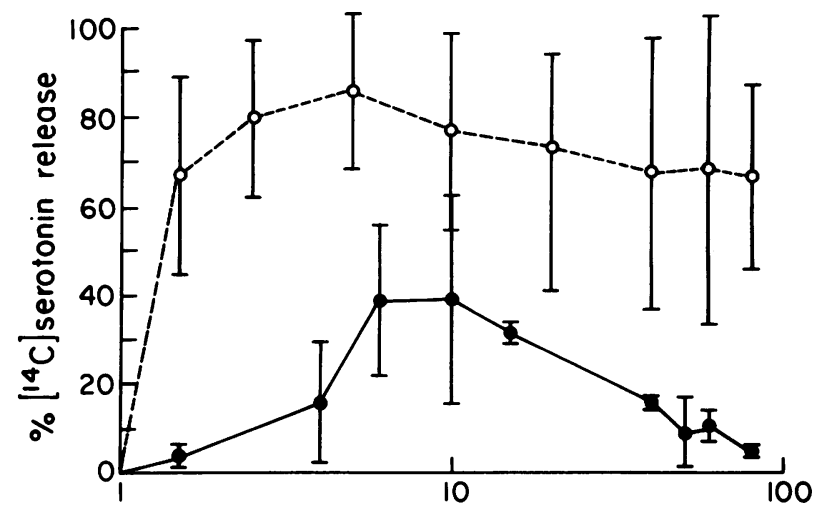

Antigen concentration $(\mu \mathrm{g} / \mathrm{ml})$

Figure $5\left[{ }^{14} \mathrm{C}\right]$ Serotonin release by ovalbumin-anti-ovalbumin complexes from platelets of three normal donors (O) and three patients with myeloproliferative syndrome (O). Bars indicate \pm 1 SD. 


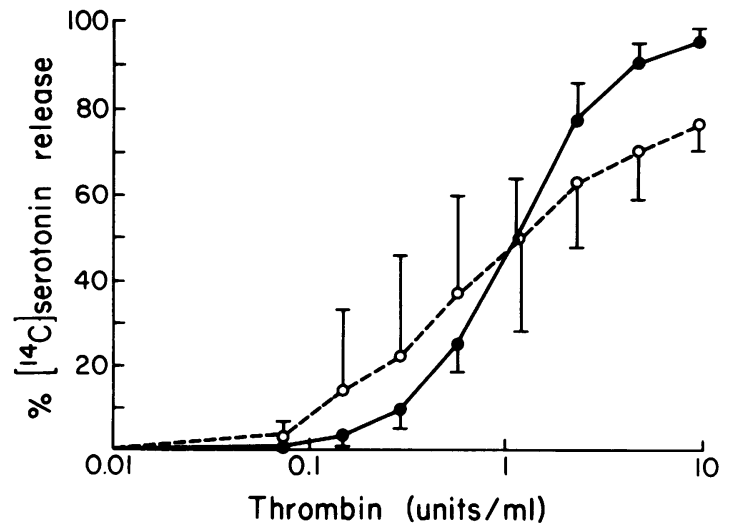

Figure $6 \quad\left[{ }^{14} \mathrm{C}\right]$ Serotonin release by thrombin from platelets of five normal donors (O) and five patients with myeloproliferative syndrome $(O)$. Bars indicate \pm 1 SD.

different FITC-conjugated immune complex, KLHanti-KLH, with normal platelets (14). This interaction also requires an intact antibody $\mathrm{Fc}$ region and is blocked by purified Fc, but unlike the ovalbuminanti-ovalbumin complex, the KLH-anti-KLH complex stains the majority of both normal and myeloproliferative platelets. In addition, the KLH-anti-KLH staining is blocked by factor VIII:antigen and ristocetin, suggesting that this immune complex interacts with the platelet membrane glycoprotein I complex, which mediates the agglutination of platelets by factor VIII: antigen and ristocetin (21). The ovalbumin-anti-ovalbumin staining is not blocked by factor VIII:antigen and ristocetin. Preliminary studies indicate that preincubation with KLH-anti-KLH complexes does not block the staining reaction elicited by ovalbuminanti-ovalbumin. It appears that these two immune complexes may be interacting with two distinct platelet $\mathrm{Fc}$ receptors. Comparison of various immune complex test systems for lymphocyte $\mathrm{Fc}$ receptors has shown wide variation in the extent of binding according to the system tested and the lymphocyte subpopulations studied (18). In addition, distinct and separate $F_{c}$ receptors have been recently described in a mouse macrophage cell line (22). The difference between normal and myeloproliferative platelets did not appear to be related to the phenomenon of activation. Thus, thrombin-treated normal platelets stained normally when incubated with FITC-conjugated ovalbumin-anti-ovalbumin. Fixed platelets did not stain with the immune complex, indicating that a certain amount of membrane fluidity may be required for the clumpy fluorescent staining pattern to be seen.

Normal platelets release serotonin in response to immune complexes or aggregated IgG $(12,13,23)$. This reaction is dependent on the $F_{c}$ region of IgG and is mediated by a platelet $\mathrm{Fc}_{\mathrm{c}}$ receptor. In the present study, the release of $\left[{ }^{14} \mathrm{C}\right]$ serotonin by the immune complex ovalbumin-anti-ovalbumin and by aggregated IgG was exaggerated in myeloproliferative platelets and was not found if thrombin was used as a stimulus to serotonin release. These results suggest that the increased expression of surface $\mathrm{Fc}$ receptors in the myeloproliferative platelets leads to increased reactivity to immune complexes as evidenced by the increased serotonin release.

The increased expression of $\mathrm{Fc}$ receptors in myeloproliferative platelets may arise at the stem cell or megakaryocyte level or may occur after the platelets have been released into the circulation. Glucose 6-phosphate dehydrogenase isoenzyme analysis of circulating platelets, neutrophils, and erythrocytes in the myeloproliferative diseases points to a common neoplastic stem cell origin for these three cell types $(24,25)$. Recently, Gilbert et al. (26) described an increase in IgG receptor-bearing neutrophils in patients with agnogenic myeloid metaplasia and polycythemia vera. As in the present study, patients with chronic myelogenous leukemia did not share this increased expression of an $\mathrm{Fc}_{\mathrm{c}}$ receptor. Thus, the finding of increased $\mathrm{F}_{\mathrm{c}}$ receptor-bearing neutrophils and platelets raises the possibility that in some circumstances there may be a transmitted alteration in a stem cell precursor that allows this increased expression.

The increased platelet $\mathrm{Fc}$ receptor expression in the myeloproliferative disorders does not appear to reflect the expansion of one population of normal platelets, for example, young platelets. The platelets of patients with postsplenectomy thrombocytosis, who might be presumed to have a larger population of young, more active platelets, do not have increased Fc receptors (Fig. 1). In addition, the platelets of two patients with immune thrombocytopenia in remission were studied and found to be normal. Fc receptor analysis of different sized platelets from normal donors did not localize the Fc receptor-positive platelets to one size population. ${ }^{2}$ It is interesting that certain patients with malignant disease demonstrated increased staining despite the absence of evidence of a myeloproliferative disease. This suggests that the increased expression of the platelet $F_{c}$ receptor may not necessarily reflect a stem cell abnormality but rather an abnormality in the platelet environment.

The modulation of $F_{c}$ receptor expression has been studied in experimental systems. For example, glucocorticoids inhibit the expression of an $\mathrm{Fc}$ receptor on a human promyelocytic cell line (27). In other myeloid leukemia lines, the $\mathrm{Fc}$ receptor can be induced by a macrophage and granulocyte-inducing

\footnotetext{
${ }^{2}$ Moore, A. Personal observations.
} 
protein. In turn, this regulatory protein can be induced by a surface-acting compound, lipid A (28). It is possible that similar humoral factors act to modulate platelet $\mathrm{Fc}$ receptor expression in the myeloproliferative disorders. Membrane receptors for peptide hormones may be regulated by the ambient concentration of the specific hormone (29). Circulating immune complexes, which are present in some patients with myeloproliferative disease (11), may elicit the expression of a specific population of platelet $\mathrm{Fc}$ receptors. It is of some interest that in preliminary studies, six of seven myeloproliferative patients reported in this study with $>80 \%$ platelet staining by the immune complex ovalbumin-anti-ovalbumin also had elevated circulating immune complexes (30). Further studies are underway to explore this relationship.

The role of the increased platelet $\mathrm{Fc}$ receptor expression in the pathogenesis of the hemorrhagic or thrombotic diathesis found in patients with the myeloproliferative syndromes remains to be determined. Our results show that the FITC-conjugated immune complexes used in these studies are not taken up by platelets when the incubation is performed in plasma. However, studies by Pfueller et al. (13) show that soluble radiolabeled IgG aggregates can bind to normal platelets in plasma, and it is possible that certain circulating immune complexes may also bind to platelets in plasma. Our studies further show that the avidity of immune complexes for platelets may depend on the nature of the antigen, the size of the complex, or on the exact ratio of antigen to antibody. In a clinical setting, it is possible that selected immune complexes bind to myeloproliferative platelets and compromise normal hemostatic functions.

\section{ACKNOWLEDGMENTS}

The authors are grateful to Drs. Richard T. Silver and Morton Coleman for referral of patients and to Mrs. Michelle Muir Lafarge and Ms. Barbara Ferris for excellent technical assistance.

This study was supported by a Specialized Center of Research grant from the National Institutes of Health HL18828 and HL-07029 and by the Arnold Krakower Foundation.

\section{REFERENCES}

1. Berlin, N. I. 1975. Diagnosis and classification of the polycythemias. Semin. Hematol. 12: 339-351.

2. Ward, H. P., and M. H. Block. 1971. The natural history of agnogenic myeloid metaplasia (AMM) and a critical evaluation of its relationship with the myeloproliferative syndrome. Medicine (Baltimore). 50: 357-420.

3. Wasserman, L. R. 1976. The treatment of polycythemia vera. Semin. Hematol. 13: 57-78.
4. Maldonado, J. E., T. Pintado, and R. V. Pierre. 1974. Dysplastic platelets and circulating megakaryocytes in chronic myeloproliferative diseases. I. The platelets: ultrastructure and peroxidase reaction. Blood. 43: 797809.

5. Zucker-Franklin, D. 1974. Ultrastructural studies of hematopoietic elements in relation to the myelofibrosisosteosclerosis syndrome, megakaryocytes and platelets (MMM or MOS). Adv. Biosci. 16: 127-143.

6. Neemeh, J. A., E. J. W. Bowie, J. H. Thompson, Jr., P. Didisheim, and C. A. Owen, Jr. 1972. Quantitation of platelet aggregation in myeloproliferative disorders. Am. J. Clin. Pathol. 57: 336-347.

7. Kaywin, P., M. McDonough, P. A. Insel, and S. J. Shattil. 1978. Platelet function in essential thrombocythemia. N. Engl. J. Med. 299: 505-509.

8. Okuma, M., and H. Uchino. 1979. Altered arachidonate metabolism by platelets in patients with myeloproliferative disorders. Blood. 54: 1258-1271.

9. Cooper, B., A. I. Schafer, D. Puchalsky, and R. I. Handin. 1978. Platelet resistance to prostaglandin $D_{2}$ in patients with myeloproliferative disorders. Blood. 52: 618-626.

10. Cooper, B., and D. Ahern. 1979. Characterization of the platelet prostaglandin $\mathrm{D}_{2}$ receptor. J. Clin. Invest. 64: 586-590.

11. Lewis, C. M., and G. D. Pegrum. 1977. Immune complexes in myeloproliferative disorders. Lancet.II: 11511153.

12. Henson, P. M., and H. L. Spiegleberg. 1973. Release of serotonin from human platelets induced by aggregated immunoglobulins of different classes and subclasses. J. Clin. Invest. 52: 1282-1288.

13. Pfueller, S. L., S. Weber, and E. F. Luscher. 1977. Studies of the mechanism of the human platelet release reaction induced by immunologic stimuli. III. Relationship between the binding of soluble IgG aggregates to the $F_{c}$ receptor and cell response in the presence and absence of plasma. J. Immunol. 118: 514-524.

14. Moore, A., G. D. Ross, and R. L. Nachman. 1978. Interaction of platelet membrane receptors with von Willebrand factor, ristocetin and the $\mathrm{Fc}$ region of immunoglobulin G. J. Clin. Invest. 62: 1053-1060.

15. Gottfried, E. L., J. Wehman, and B. Wall. 1976. Electronic platelet counts with the Coulter counter. Am. J. Clin. Pathol. 66: 506-511.

16. von Behrens, W. E. 1975. Mediterranean macrothrombocytopenia. Blood. 46: 199-208.

17. Rabellino, E. M., R. L. Nachman, N. Williams, R. J. Winchester, and G. D. Ross. 1979. Human megakaryocytes. I. Characterization of the membrane and cytoplasmic components of isolated marrow megakaryocytes. J. Exp. Med. 149: 1273-1287.

18. Winchester, R. J., T. Hoffman, M. Ferrarini, G. D. Ross, and H. G. Kunkel. 1979. Comparison of various tests for $\mathrm{Fc}$ receptors on different human lymphocyte subpopulations. Clin. Exp. Immunol. 37: 126-133.

19. Weksler, B. B., C. W. Ley, and E. A. Jaffe. 1978. Stimulation of endothelial cell prostacyclin production by thrombin, trypsin and the ionophore A 23187. J. Clin. Invest. 62: 923-930.

20. Wroblewski, F., and J. S. La Due. 1955. Lactic dehydrogenase activity in blood. Proc. Soc. Exp. Biol. Med. 90: $210-213$.

21. Nachman, R. L., E. A. Jaffe, and B. B. Weksler. 1977. Immunoinhibition of ristocetin-induced platelet aggregation. J. Clin. Invest. 59: 143-148. 
22. Unkeless, J. C., G. Kaplan, H. Plutner, and Z. A. Cohn. 1979. Fc-receptor variants of a mouse macrophage cell line. Proc. Natl. Acad. Sci. U.S.A. 76: 1400-1404.

23. Mueller-Eckhardt, C., B. Mayser, and D. Heinrich. 1977. The problem of platelet autoantibodies. II. The applicability of the ${ }^{14} \mathrm{C}$-serotonin release test. Vox Sang. 33: 234-245.

24. Adamson, J. W., P. J. Fialkow, S. Murphy, J. F. Prchal, and L. Steinmann. 1976. Polycythemia vera: stem-cell and probable clonal origin of the disease. N. Engl. J. Med. 295: 913-916.

25. Jacobson, R. J., A. Salo, and P. J. Fialkow. 1978. Agnogenic myeloid metaplasia: a clonal proliferation of hematopoietic stem cells with secondary myelofibrosis. Blood. 51: 189-194.

26. Gilbert, H. S., R. Goldberg, and L. Ward. 1979. In- creased circulating neutrophils with surface receptor activity for immunoglobulin $G$ in polycythemia vera and myeloid metaplasia. Blood. 53: 1106-1113.

27. Crabtree, G. R., A. Munck, and K. A. Smith. 1979. Glucocorticoids inhibit expression of Fc receptors on the human granulocytic cell line HL-60. Nature (Lond.). 297: 338-339.

28. Weiss, B., and L. Sachs. 1978. Indirect induction of differentiation in myeloid leukemic cells by lipid A. Proc. Natl. Acad. Sci. U.S.A. 75: 1374-1378.

29. Catt, K. J., J. P. Harwood, G. Aguilera, and M. L. Dufau. 1979. Hormonal regulation of peptide receptors and target cell responses. Nature (Lond.). 280: 109-116.

30. Gordon, B., M. Coleman, P. Romano, and N. K. Day. 1980. Circulating immune complexes associated with hypocomplementemia in myelofibrosis. Clin. Res. 28: 492A. 